\title{
26 MAKING SENSE OF TECHNOLOGICAL FRAMES: Promise, Progress, and Potential
}

\author{
Elizabeth Davidson \\ David Pai \\ University of Hawaii, Manoa
}

\begin{abstract}
In a seminal paper, Orlikowski and Gash (1994) articulated a conceptual framework for technological frames of reference (TFR) to lay the groundwork for a systematic approach to socio-cognitive research on information technology. This work is widely cited as a justification for social and socio-cognitive analysis of IT, but a limited number of studies utilizing and further developing the frames concept have been published in the ensuing decade. In this paper, we review the promise of the technological frame concept, assess theoretical and methodological progress evident in TFR publications, and consider how potential contributions of TFR may be realized in future research. In doing so, we consider how limitations in TFR research to-date might be addressed, including the feasibility of a rapprochement with quantitative research methods, of TFR analysis at the industry level of analysis, and of action research approaches.
\end{abstract}

Keywords: Technological frames of reference, qualitative research methods, social cognition, social construction of technology, information systems research

\section{INTRODUCTION AND MOTIVATION}

In 1994, Wanda Orlikowski and Debra Gash introduced the concept of technological frames of references (TFR) to the Information Systems community in their paper entitled "Technological Frames: Making Sense of Information Technology in Organizations." The influence of the TFR concept in the IS and other academic com- 
munities is evident in several ways. A citation search on the ISI Social Science Citation Index yielded a list of 52 citations, ranging from traditional IS research journals to engineering and computer science outlets (e.g., IEEE Transactions on Engineering Management, Human-Computer Interaction, and Journal of the Operations Research Society) and beyond IT to technology journals (e.g., Science, Technology and Human Values and Technology Analysis and Strategic Management, Social Studies of Science). Using an Internet search engine (Google) to target this paper, we found hundreds of "hits," ranging from Ph.D. seminar reading lists to citations in unpublished white papers and research descriptions posted to Internet Web sites.

Given the apparent wide appeal and exposure of the technological frames concept, we were surprised to find relatively few published reports of research that actually conducted a TFR analysis or further developed the theoretical framework. Instead, publications citing Orlikowski and Gash's paper typically referred to the notion of frames in passing, or more generally to socio-cognitive approaches. A few papers indicated that the frames concept would be actively engaged, then failed to do so, pursuing other theoretical approaches instead. Intrigued by this seeming contradiction between the intuitive appeal of the TFR concept and its actual use in IS research practice, we examine the promise for theoretical and practical contributions outlined in Orlikowski and Gash's framework and the theoretical, methodological, and practical progress evident in the eight journal and conference publications we did locate. From this analysis, we consider limitations in TFR research and suggest several ways in which its potential might be realized in future work.

The paper is organized as follows. We first review key aspects of the technological frames concept outlined by Orlikowski and Gash, and its intellectual roots in the social construction of technology and organizational cognition literatures. We then review publications that have utilized the frames concept and, guided by Orlikowski and Gash's blueprint for future research, assess how these studies have contributed to development of the TFR concept. In our discussion, we consider aspects of TFR research that may constrain its use in IS research and highlight various approaches to help researchers interested in socio-cognitive investigations to realize the potential contributions of this framework. In doing so, we consider whether rapprochement with quantitative research methods is feasible and what the theoretical and practical implications might be. We note that action research is a particularly promising approach for TFR studies that could heighten contributions to practice. Finally, we suggest that TFR analysis could be used to better understand frame formation around emerging technologies within organizational fields, and that such studies could inform intra-organizational analysis of frame formation and change as well as interorganizational analysis.

\section{CHARACTERIZING TECHNOLOGICAL FRAMES}

Orlikowski and Gash (1994) based their argument for technological frames as a theoretical lens in IS research on the premise that people act on their interpretations of the world (Berger and Luckmann 1967; Weick 1979), including their interpretations regarding technologies in organizations. A variety of IS researchers had previously addressed socio-cognitive and interpretive issues, focusing particularly on the ways in 
which technology designers' cognitive understanding influences the design of technical artifacts (cf. Boland 1978, 1979; Bostrom and Heinen 1977; Dagwell and Weber 1983; Markus and Bjørn-Andersen 1987) and on the alignment of users' expectations with the intended design (cf. Ginsberg 1981). To lay the groundwork for a socio-cognitive perspective in IT research focused on frames of reference, Orlikowski and Gash defined technological frames as "that subset of members' organizational frames that concern the assumptions, expectations, and knowledge they use to understand technology in organizations. This includes not only the nature and role of the technology itself, but the specific conditions, applications, and consequences of that technology in particular contexts" (p. 178). They posited that frames exist at the individual level, but individuals within relevant social groups tend to develop shared frames of reference that guide their interactions around technology and their understanding and use of technology. The groups they identified in an empirical study included technologists who implemented organizational IT systems, users of these systems, and managers who decided which technologies to adopt or champion.

Orlikowski and Gash's major interest was sensemaking around information technologies and organizational changes related to technology, particularly the difficulties that arise when the frames of relevant social groups differ. They defined congruence as the alignment of TFRs along key elements, that is, similarity in structure (common categories) and content (common values) and posited that when there is incongruence in the frames of key organizational stakeholder groups, problems such as misaligned expectations, contradictory actions, resistance, skepticism, and poor appropriation of IT may result (p. 180). In their empirical study, Orlikowski and Gash identified incongruence between the interpretations of a new IT of managers, users, and technologists and their expectations for its uses, which contributed to underutilization of the system.

To better understand the promise and limitations of the TFR concept in IS research, we examined the intellectual roots of Orlikowski and Gash's framework in two literatures: research on the social construction of technology (SCOT) (cf. Bijker 1995; Bijker et al. 1987) and organizational studies of social cognition (cf. Bartunek 1984; Gioia 1986; Weick 1979; for a comprehensive literature review, see Walsh 1995). Here, we reflect on how Orlikowski and Gash selectively drew from these literatures in their framework; later we will consider how further developing these intellectual roots might benefit future TFR research.

\subsection{Technological Frames and SCOT}

Orlikowski and Gash derived their notions of interpretive flexibility of technology (also see Orlikowski 1992), relevant social groups, and shared frames primarily from SCOT theories. Orlikowski and Gash's articulation of the TFR concept has similarities with Bijker's (1995) definition of a technological frame: some frame elements Bijker defined- - goals, key problems, users' practices, and so on - are evident in the frame dimensions Orlikowski and Gash identified (e.g., technological strategy motivation, criteria for success, ease-of-use, training); other Bijker elements, such as tacit knowledge, are implicit in Orlikowski and Gash's definition of TFR as taken-for-granted 
assumptions. A substantive difference is that Orlikowski and Gash's frame concept is strictly socio-cognitive and does not include the technology artifact, whereas Bijker includes cognitive, social, and material elements (particularly, the technology artifact) within his definition of a frame (p. 126).

There are other notable differences in the TFR concept and SCOT analysis. Orlikowski and Gash defined TFRs as individual, socio-cognitive structures that may be shared among members of a relevant social group - a definition akin to group-level analysis in social cognitive research. Bijker defined technological frames as social, rather than socio-cognitive, structures, noting "a technological frame structures the interactions among the actors of a relevant social group. Thus it is not an individual's characteristic, nor a characteristic of systems or institutions; technological frames are located between actors, not in actors or above actors" (p. 123). Orlikowski and Gash's research interests are consistent with SCOT goals of understanding how frames influence the design and interpretations of technology artifacts. However, their use of TFR analysis varied from SCOT research in level of analysis and emphasis. Orlikowski and Gash's framework directs attention to the interpretive influences of existing TFRs within organizations, particularly in situations in which incongruence exists, and of frame changes resulting from organizational IT adoption. SCOT studies such as Bijker's consider technological frames at the societal level and examine processes through which frames take shape and stabilize or change. Orlikowski and Gash characterized TFRs as a process theory, but they did not explicitly incorporate SCOT process concepts such as closure (acceptance of a dominant technology interpretation across relevant social groups) or stabilization (strengthening of a TFR within a social group).

\subsection{Technological Frames and Social Cognitive Studies}

To highlight the influence of the organizational social cognitive literature on the TFR concept, we draw on Walsh's (1995) comprehensive synthesis and review, which incorporated studies and findings cited by Orlikowski and Gash. Walsh coined the term knowledge structure to represent the myriad constructs that have been used in social cognitive research (i.e., frames of reference, schema, interpretive schemes, scripts and so on), defining them as "a mental template that individuals impose on an information environment to give it form and meaning" (p. 281). Knowledge structures are individually held, although much research has been conducted at the group (cf. Gioia 1986; Isabella 1990; Walsh and Farley 1986), organizational (cf. Bartunek and Moch 1987; Daft and Weick 1984) and even industry (cf. Porac et.al 1989) levels of analysis. Orlikowski and Gash grounded their TFR concept at the individual level but addressed group level frames by defining them as shared aspects of individual frames. In doing so, they avoided the debate about whether higher-level socio-cognitive structures exist, independent of individual structures. Walsh cautioned, however, that we should "view organizational cognition as much more than some kind of aggregation or even congregation of individual cognitive processes" (p. 304).

Organizational research on social cognition generally examines frame content (domains of knowledge) or structure (organization and integration of knowledge), with studies of content far outnumbering studies of structure (Walsh 1995). By examining 
sensemaking related to information technology in organizations, Orlikowski and Gash identified frame content in a new context for social cognitive research; their empirical study identified three domains relevant to the adoption of a groupware technology (nature of technology, technology strategy, technology-in-use). They cautioned that these frames are not all-inclusive nor will they necessarily apply across contexts; instead, frames are context-sensitive and should not be defined a priori.

Integration and differentiation are two aspects of frame structure typically considered in organizational research, reflecting cognitive theories of information processing that underlie much social cognitive research (Walsh 1995). Structural studies at the group level ofhave relied primarily on cause mapping (Weick and Bourgon 1986), network analysis (Krackhardt 1987), or multidimensional scaling (MDS) techniques (Walsh et al. 1988) to derive knowledge structures (Walsh 1995, p. 301). Orlikowski and Gash were primarily concerned with the social rather than the cognitive influences of frames and thus gave little attention to these structural dimensions. Structure was briefly discussed in terms of domains of knowledge and the implications for frame congruence.

We define the notion of congruence in technological frames as referring to the alignment of frames on key elements or categories. By congruent, we do not mean identical, but related in structure (i.e., common categories of frames) and content (i.e., similar values on the common categories)" (Orlikowski and Gash 1994, p. 180).

Organizational researchers have examined how frames develop, how they represent the information environment, and, particularly, how they are used in managerial sensemaking, decision-making, and action (Walsh 1995). Similar to many organizational social cognitive studies (cf. Bartunek 1984; Bartunek and Moch, 1987, Daft and Weick 1984; Gioia 1986), Orlikwoski and Gash's central interest was the use of technological frames in sensemaking and interpretation related to IT and organizational change, particularly the consequences of frame use where frame incongruence exists. They suggested that recognition of incongruence and interventions aimed at overcoming it might result in frame change (i.e., frame alignment). Issues related to frame development and frame representation of an informational environment were not explicitly addressed.

\section{DEVELOPMENTS IN TFR RESEARCH}

We conducted a literature search to assess how Orlikowski and Gash's (1994) TFR framework has influenced IS research practice. To identify published reports employing TFR analysis, we conducted a citation search on ISI Social Science citation index. This search (conducted in July, 2003) produced 52 citations to Orlikowski and Gash's paper, but on further examination, only five publications actually conducted some form of TFR analysis. We also searched electronic journal index databases EBSCO and ABI/ INFORM (ProQuest) on the terms "technology frame" and "technological frame." Additionally, we searched for the same terms on the ACM Digital Library and eMISQ (via the AIS website www.aisnet.org). These searches produced three additional studies, 
all conference papers, which utilized TFR analysis, for a total of eight published research reports. We also searched the Internet but found, despite numerous "hits," only white papers or research descriptions. Since we could find no evidence these papers had been published in a refereed academic journal or conference proceedings, we did not include them in our analysis, but we do recognize them as evidence of the growing interest in TFR research. Table 1 lists the eight published studies we identified and summarizes key aspects of each; Orlikwoski and Gash's study is included for comparison.

Orlikowski and Gash's paper appears to have established a genre for TFR studies, which other researchers have utilized in a variety of organizational and technological settings. All of the TFR studies we identified involved in-depth case studies at one or more organizations, utilized interviews as a key source of data collection, and relied (the majority, exclusively) on qualitative data analysis methods. Of these publications, five reported on studies of technology development or implementation, whereas one used TFR analysis to assess training related to technology, one to assess policy formation associated with a new technology, and one to examine operational support. Similar to Orlikowski and Gash's study, six studies examined frames at a point in time (snapshot) although some historical reconstructions were attempted from interview data or written documents; one longitudinal study examined shifts in frames during an extended requirements study and another examined framing processes in a manner akin to SCOT analysis. ${ }^{1}$ Finally, six of the eight studies were primarily concerned with frame incongruence, as was Orlikowski and Gash' study, while two examined frame change processes and consequences.

To assess how the TFR framework has been used and extended in these studies, we revisited Orlikowski and Gash's suggestions for future research and categorized the areas they identified as primarily theoretical development, methodological enhancement, or contributions to practice. We organize our discussion of subsequent TFR studies around each area.

\subsection{Theoretical Developments}

Defining additional frame domains and content: Orlikowski and Gash identified three general domains of TFRs, which were relevant in their empirical study (nature of technology, technology strategy, technology in use), but they cautioned that other frame domains might be relevant in different contexts. At first look, the TFR studies we reviewed suggest no common or general frame domains have emerged, that frame domains are in fact context-specific. Each paper used unique titles for frame domains,

${ }^{1}$ Our literature search revealed a number of studies utilizing the SCOT technological frame approach, or mentioning both SCOT and TFR, but pursuing SCOT analysis. Because we wanted to focus on Orlikowski and Gash's TFR framework, we did not include these studies. The McLoughlin et al. (2000) study incorporated sufficient aspects of both SCOT/TFR that we included it here 
Table 1. Academic Publications Reporting on a TFR Study and Analysis

\begin{tabular}{|c|c|c|c|}
\hline Research & Study Context & Frame Domains & User Groups \\
\hline $\begin{array}{l}\text { Orlikowski } \\
\text { and Gash } \\
(1994)\end{array}$ & $\begin{array}{l}\text { Lotus notes implementation } \\
\text { in large consulting firm } \\
\text { - Early, ongoing implemen- } \\
\text { tation } \\
\text { - Snapshot of frames }\end{array}$ & $\begin{array}{l}\text { Nature of technology } \\
\text { Technology strategy } \\
\text { Technology-in-use }\end{array}$ & $\begin{array}{l}\text { Technologists } \\
\text { Users }\end{array}$ \\
\hline $\begin{array}{l}\text { Barrett } \\
\text { (1999) }\end{array}$ & $\begin{array}{l}\text { EDI service in the London } \\
\text { insurance market } \\
\text { - Longitudinal study of } \\
\text { development, intro- } \\
\text { duction, system use } \\
\text { - Snapshot of frames } \\
\text { derived from cultural } \\
\text { assumptions }\end{array}$ & $\begin{array}{l}\text { Nature of } \\
\text { technological change } \\
\text { Nature of business } \\
\text { transactions } \\
\text { Importance of market } \\
\text { institutions }\end{array}$ & $\begin{array}{l}\text { IT professionals } \\
\text { Senior managers } \\
\text { Brokers and } \\
\text { underwriters } \\
\text { (Users) }\end{array}$ \\
\hline $\begin{array}{l}\text { Davidson } \\
\text { (2002) }\end{array}$ & $\begin{array}{l}\text { Sales information system at } \\
\text { an insurance company } \\
\text { - Longitudinal study of } \\
\text { requirements and pilot } \\
\text { implementation } \\
\text { - Frame change over time }\end{array}$ & $\begin{array}{l}\text { IT delivery strategies } \\
\text { IT capabilities and } \\
\text { design } \\
\text { Business value of IT } \\
\text { IT-enabled work } \\
\text { practices }\end{array}$ & $\begin{array}{l}\text { System } \\
\text { developers } \\
\text { System } \\
\text { constituents } \\
\text { Executive }\end{array}$ \\
\hline $\begin{array}{l}\text { Gallivan } \\
(2001)\end{array}$ & $\begin{array}{l}\text { Reskilling IT professionals } \\
\text { for client/ server techno- } \\
\text { logies at a telecommunica- } \\
\text { tions company } \\
\text { - Implementation } \\
\text { - Snapshot of frames }\end{array}$ & $\begin{array}{l}\text { Vision of reskilling/ } \\
\text { type of change }\end{array}$ & $\begin{array}{l}\text { Change } \\
\text { managers } \\
\text { IT professionals } \\
\text { Miscellaneous } \\
\text { others }\end{array}$ \\
\hline Khoo (2001) & $\begin{array}{l}\text { Design of peer review } \\
\text { policies for the Digital } \\
\text { Library for Earth System } \\
\text { Education (DLESE) } \\
\text { - Design, implementation } \\
\text { - Snapshot of frames }\end{array}$ & $\begin{array}{l}\text { N/A (mentions library } \\
\text { models and peer } \\
\text { review models) }\end{array}$ & $\begin{array}{l}\text { "Communities } \\
\text { of perception" } \\
\text { Library that is } \\
\text { digital } \\
\text { Digital artifact } \\
\text { as library }\end{array}$ \\
\hline $\begin{array}{l}\text { Lin and } \\
\text { Cornford } \\
(2000)\end{array}$ & $\begin{array}{l}\text { Replacement of an e-mail } \\
\text { system in a financial } \\
\text { institution } \\
\text { - Pre-implementation } \\
\text { - Snapshot of frames }\end{array}$ & $\begin{array}{l}\text { The nature of problems } \\
\text { Requirements for the } \\
\text { system } \\
\text { Images of implemen- } \\
\text { tation } \\
\text { Issues around use }\end{array}$ & $\begin{array}{l}\text { Office IS group } \\
\text { User group } \\
\text { Management } \\
\text { group }\end{array}$ \\
\hline $\begin{array}{l}\text { McLoughlin } \\
\text { et al. (2000) }\end{array}$ & $\begin{array}{l}\text { Implementation of team- } \\
\text { based cellular manufacturing } \\
\text { technology in three } \\
\text { companies } \\
\text { - Longitudinal during } \\
\text { implementation } \\
\text { - Process of frame closure } \\
\text { and stabilization } \\
\end{array}$ & $\begin{array}{l}\text { Treated as unidimen- } \\
\text { sional (a "frame" in the } \\
\text { SCOT sense) }\end{array}$ & $\begin{array}{l}\text { Various } \\
\text { stakeholders }\end{array}$ \\
\hline
\end{tabular}




\begin{tabular}{|l|l|l|l|}
\hline \multicolumn{1}{|c|}{ Research } & \multicolumn{1}{|c|}{ Study Context } & \multicolumn{1}{c|}{ Frame Domains } & \multicolumn{1}{c|}{ User Groups } \\
\hline $\begin{array}{l}\text { Sahay, et al. } \\
(1994)\end{array}$ & $\begin{array}{l}\text { Implementation of GIS } \\
\text { technology } \\
\text { - Implementation } \\
\text { - Snapshot of frames }\end{array}$ & $\begin{array}{l}\text { N/A (identified a } \\
\text { detailed list of } \\
\text { issues/problems with } \\
\text { GIS technology) }\end{array}$ & $\begin{array}{l}\text { Experts (IT) } \\
\text { Users }\end{array}$ \\
\hline $\begin{array}{l}\text { Shaw et al. } \\
(1997)\end{array}$ & $\begin{array}{l}\text { Effectiveness of computer } \\
\text { systems support at elevator } \\
\text { company }\end{array}$ & $\begin{array}{l}\text { Technology in use } \\
\text { Technology strategy }\end{array}$ & $\begin{array}{l}\text { MIS staff } \\
\text { Management } \\
\text { Ond-users }\end{array}$ \\
& $\begin{array}{l}\text { Operations, ongoing } \\
\text { support }\end{array}$ & technology & Nature of technology \\
& Snapshot of frames & & \\
\hline
\end{tabular}

identified different numbers of domains, and described domain content in contextually bound terms. However, a close examination of the frame domains described in these research reports suggests some similarities across settings. For example, Barrett's (1999) "nature of technological change" and Davidson's (2002) "business value of IT" overlapped with Orlikowski and Gash's "technology strategy" category. Lin and Cornford's (2000) "requirement for the system" and Davidson's "IT capabilities and design" bore resemblance to the "nature of technology" domain. Aspects of the "technology in use" category were evident in "nature of business transactions" (Barrett 1999), "IT-enabled work practices" (Davidson 2002) and "issues around use" (Lin and Cornford 2000). This variation in naming, number, and precise definition of frame domains is consistent with the idiographic nature of TFR analysis.

Several studies introduced new frame domains. Barrett identified "importance of market institutions" within the organizational field he examined: "these cultural assumptions consider not only patterns of meaning or meaning structures held by these groups, but also how they are embedded in relations of power and norms of the organization" (pp. 3-4). By incorporating analysis of cultural elements, he addressed institutional and structural influences of TFRs on actors' interpretations and actions around IT adoption. Orlikowski and Gash briefly discussed the institutional implications of frames but did not develop this topic in their paper. Davidson highlighted "IT delivery strategies" as a salient domain during requirements determination and demonstrated possible conflicts between this domain and the "business value of IT" domain. Gallivan (2001) applied TFR analysis to re-skilling of IT workers. Linking TFRs to the type of organizational change envisioned, he discussed "visions of re-skilling" as first, second or third order changes.

Understanding of incongruence, frame convergence, and divergence: Orlikowski and Gash suggested the concept of incongruence would require further development to better understand where incongruence occurs, the degree of incongruence that might be tolerable, and the processes through which incongruence might increase or decrease. The studies in Table 1 offered a variety of insights on incongruence. Sahay et al. (1994) proposed an analytic method (multidimensional scaling or MDS) for quantitatively assessing the degree of incongruence in frames, which we will discuss shortly. However, Davidson's analysis illustrated that incongruence may vary across frame domains, relevant social groups, and over time as the salience of domains shift in response to 
change triggers. This socio-cognitive instability could frustrate methodological attempts to quantify and capture frame incongruence within domains across groups. Lin and Cornford drew on ANT theory to address incongruence, suggesting that frame alignment could be managed by one group's social translation of other group's frames toward their own frame.

Khoo (2001) posited that in some settings, the degree of frame difference might exceed incongruence and defined an incommensurate level of interaction as

one in which the concepts of one frame cannot be understood in terms of the concepts of the other frame... while incongruence allows for the same data to be interpreted in different ways, incommensurability stresses that the data are in themselves differently constituted (p. 158).

Khoo drew parallels to Kuhnian paradigms, suggesting relevant social groups are defined by their technological frames and their interpretations of a technology; this approach is akin to SCOT analysis, although he does not reference SCOT theorists.

Frame change over time, change triggers: Similar to Orlikowski and Gash, six of the eight studies we identified reported the TFR analysis primarily as a snapshot of frames, or treated frames as static and unchanging over time. Thus, they did not address frame change or change triggers. Without longitudinal data, change processes are difficult to detect. Past frames can be reconstructed using retrospective interviews and written project archives, as Lin and Cornford apparently did to examine frame changes through social translation processes. Reconstructing past frames from interview data can be subject to retrospective sensemaking, that is, of reconstructing past frames inaccurately through the lens of current frames, and lacks the detailed access to the oral discourse that real- time field data collection allows.

Davidson's combination of retrospective interviews, project document reviews, interviews, and longitudinal on-site observations to reconstruct earlier frames and to trace current frames illustrated how various data collection approaches, in combination, allowed a longer timeframe for analysis of frame change than typically would be feasible for an on-site field study. In Davidson's study, frame change was evident in shifts in frame domain salience, triggered by reorganizations, environmental stimuli, or technology changes, rather than in changes in domain content. For example, the "ITenabled work practices" domain was not salient to developers or users during design or installation, but when technology was actually implemented and used, this domain became highly salient to users, and latent incongruence between technologists' and users' frames emerged. Salience shifts were evident in the oral discourse as changes in project and design metaphors and narratives; these subtle discourse changes would be difficult to detect without ongoing field observation.

Frame tolerance or rigidity: Orlikowski and Gash's TFR framework did not explicitly consider structural aspects of frames that have been addressed in the organizational social cognition literature. Nor did the framework incorporate process concepts such as stabilization and closure from SCOT theory. The authors suggested further research would be needed to investigate frame tolerance and rigidity and their association with incongruence and its consequences. Because the majority of publications we examined produced a static snapshot of frames, these issues have not 
yet been thoroughly explored in TFR research. However, two studies, employing longitudinal designs, did consider frame structuring processes. McLoughlin et al. (2000) examined evidence of frame closure and stabilization in the process of adopting and adapting to a cell manufacturing technology and linked these frame development stages to political processes in the firms studied. Davidson's analysis demonstrated how lack of stability in frames and in the framing process destabilized the requirements determination process. She suggested that excessive stability (or fluidity) in frames could contribute to unwarranted escalation (or de-escalation) of commitment to an IT project despite contradictory contextual cues (Keil and Robey 1999). Neither study examined frame structure explicitly, leaving this area of the TFR framework relatively unexplored and undefined.

Complementing political analysis: Orlikowski and Gash maintained that the TFR concept

allows us to explain and anticipate outcomes that are not captured by other perspectives, such as political or structural contingency models. For example, while a political perspective may explain particular outcomes that are due to the loss or gain of power by a group, it cannot explain contradictory outcomes due to different interpretations of a technology (p. 199).

Orlikowski and Gash's concern with interventions to resolve incongruence implies that some groups will change their frames to align with other groups' frames. While frame change may occur through education and experience, power and influence are likely to come into play. In fact, although the TFR studies we examined did highlight interpretive processes, political processes were tightly interwoven in the analysis, suggesting that it is difficult to isolate socio-cognitive from power/political processes (Markus and BjørnAndersen 1987). Davidson observed, based on her analysis, that "Interpretive power is brought to bear when dominant frames form the basis from which others develop their understanding of technology." Lin and Cornford drew on actor-network to explain how one group manipulated another's frames related to the new technology to gain support for their own technology selection. Barrett's TFR analysis at the organizational field level highlighted the power relations embedded in cultural norms and interpretations that form the basis of frames. And McLoughlin et al. explicitly linked their TFR analysis to political processes that were brought to bear to establish a dominant frame and to extend its influence.

\subsection{Methodological Refinements}

TFR analysis requires eliciting deeply held assumptions, expectations, and knowledge and assessing incongruence and inconsistencies in frames thus described. Orlikowski and Gash utilized interview data, which they analyzed using qualitative content analysis methods. These methods are well suited to the interpretive assumptions underlying the research framework but are labor intensive, difficult to specify, and hard to replicate. The eight publications we identified nonetheless all used similar, qualitative methods, albeit with some variations. In keeping with Orlikowski and Gash's call to 
attend to language and metaphors, Davidson examined the influence of metaphors and stories. Metaphors were cast as symbolic indicators of TFRs, as well as sensemaking devices that aided in interpretation. They also played a communicative role in sharing meaning among organization members. Organizational stories had similar functions. Shaw et al. (1997) used a qualitative approach to analyzing frames with quantitative measures to assess end-user satisfaction with support services. However, the authors' causal hypothesis that frame incongruence resulted in dissatisfaction was not analytically supported.

Moving further into the quantitative realm for TFR analysis, Sahay et al. used interviews to collect data and content analysis to identify a list of implementation problems with a geographical information system technology. They then used a dualcoding technique to collect quantitative rating data to compare how each user group viewed these problems. With this data, they quantitatively assessed inconsistencies, or incongruence, between groups over each of the specific problems. Their use of dualcoding integrated qualitative and quantitative approaches for identifying frame domains and content, providing a systematic method to quantify congruence/incongruence across frame domains and user groups. The goal of this paper was to illustrate the multidimensional scaling method in TFR analysis; the quantitative analysis was not tied to measurements ofoutcomes such as dissatisfaction with the system. Thus, the analytic advantages of quantitative measurement of TFR incongruence were not fully demonstrated.

\subsection{Contributions to Practice}

Orlikowski and Gash suggested three primary ways in which TFR analysis could benefit practice. First, frames could be identified and articulated early in technology projects to determine if incongruence exists among relevant social groups, allowing an opportunity for groups to reconcile differences. Lin and Cornford's study illustrated how organizational groups might recognize and adjust expectations in early project stages. Second, changes in frames could be tracked over time to determine if incongruence is developing or if problems due to interpretation are likely. Davidson and McLoughlin et al. demonstrated how longitudinal frame analysis might be conducted. Finally, frame analysis could be directed toward technologists, particularly when external consultants are involved in implementation efforts. Although technologists' TFRs were examined in most of the studies we reviewed, intra-group frame inconsistency or incongruence was not the focus of the research.

These studies illustrate the potential for application of TFR analysis in practice but they do not give direct evidence that this approach has actually affected practice. If it has, we should see its influence in two ways. One is if organization members, or external consultants who act as change agents or project managers, utilize TFR analysis in project intervention. We searched the Internet to seek out business press reports, but we found only academic research references. This does not mean that TFR analysis is not used in practice, only that there are no business press reports. A second avenue for influencing practice is through action research projects conducted jointly by academic researchers and practitioners. One of the studies we identified, the McLoughlin et. al. study of cell manufacturing technologies, was conducted as an action research project. 
The other studies may have reported results to research sites, a practice advocated by Orlikowski and Gash, and in this way had a direct influence on practice at the research sites, but if so, the results are not reported in these papers.

\section{REALIZING THE POTENTIAL OF TECHNOLOGICAL FRAMES}

Technological frames of reference provide a flexible approach to explore interpretive issues in information technology design, implementation, and use. Our analysis outlines the contributions Orlikowski and Gash (1994) hoped their framework would make in IS research and highlights further developments in TFR analysis in subsequent studies. However, despite its apparent intuitive appeal, the TFR framework has not generated the level of research activity that theories such as the technology acceptance model (Davis 1989) have spawned. Why, if technological frames provide a necessary and useful perspective to study persistent issues with technology design, adoption, and organizational change, have few actual studies been performed and the results published? And how could interest in TFR analysis be energized? Building on our earlier analysis, we now consider three areas that pose significant challenges in TFR studies and suggest possible ways in which these challenges might be managed.

\subsection{Is There a Better Way to Identify and Analyze TFRs?}

Methodologically, TFR researchers have relied on organizational case studies and qualitative research methods (open-ended interview techniques, content analysis, grounded theory techniques) to elicit frame domains. These are rigorous methods to explain what has happened in a given set of circumstances, but they are not easily scaled for multiple case studies or survey research. Collecting and analyzing data on technological frames is labor intensive and time-consuming. Moreover, the researcher's efforts to define frames in one research setting cannot be easily amortized in subsequent studies in other research sites, due to idiographic definition of frames. Thus, it is difficult to build a comparative body of empirical findings, as has been done with positivist, quantitative research streams, for example, TAM studies using standard instruments for ease of use and usefulness constructs.

Could a quantitative method to measure and compare frames at individual and group levels, and to more precisely measure frame incongruence, increase research interest in TFR analysis? Would such an approach be consistent with epistemological assumptions about technological frames? Idiographic, qualitative approaches have been used in organizational social cognitive studies, but a number of organizational researchers have also used quantitative methods for frame assessment (for a summary, see Walsh 1995). This suggests that alternatives to qualitative content analysis methods may be possible.

Sahay et al. (1994) illustrated a mixed qualitative/quantitative method for TFR research-multidimensional scaling (MDS). They first used interviews to solicit dimensions from study subjects, then used content coding to develop the frame dimensions. Subjects were asked to assess and order each dimension using an MDS instrument; the results were subjected to statistical analysis to analyze frame similarities and differences. 
This methodological approach was not inconsistent with the idiographic assumptions of TFR analysis: frames were defined within the research context. Furthermore, subjects were prompted to provide frame domains in their own words, although some structuring by researchers happened during content analysis. Used in this way, MDS can be consistent with interpretive assumptions underlying the TFR framework.

Repertory grid techniques are another set of quantitative methods that could be employed "to better understand how various information system stakeholders (users, managers, information system professionals) think about IT in their organizations" (Tan and Hunter 2002, pp. 39-40). At the core of these techniques is identification of elements, constructs, and links between them. Elements and constructs may be supplied to the research subjects, or elicited from them. An individual's construct system can then be subjected to a variety of analysis, from a basic content analysis to more sophisticated statistical techniques to quantify individual structural elements such as element distance, construct centrality, and element preference, as well as comparative structural measures such as cognitive differentiation, complexity, and integration (Tan and Hunter 2002, p. 49). This cognitive mapping tool could be used to elicit individuals' technological frames (cognitive maps), evaluate differences between frames, and monitor changes in frames over time. Tan and Hunter (2002) suggested that using the repertory grid technique would not only aid researchers studying cognitive processes, but would inform the practitioners who participate in exercises, helping them to recognize and possibly adjust tacit assumptions about IT.

We are cautiously optimistic that techniques such as MDS and repertory grid could make the task of TFR data analysis more manageable. By providing techniques to assess and compare frame structure, these techniques could facilitate theory development related to the structural aspects of frame incongruence, an area that has received little attention in TFR research thus far. On the other hand, while these techniques can be applied in ways that are consistent with the interpretive underpinnings of TFRs, widescale adoption of their use might be the first step down the slippery slope to a positivist straightjacket. The putative objectivity and scientific precision of quantitative, statistical methods would likely require similarly precise measurement methods for outcome variables, promote nomological rather than idiographic definitions of frame domains to promote cross-study comparisons, and inevitably lead to generalized cause-effect hypothesis about independent and dependent theoretical constructs. If such a transformation of TFR assumptions and methods were to occur, could the move from organizational field studies to controlled laboratory experiments be far behind?

We paint this scenario with tongue-in-cheek, and in the spirit of the 2004 IFIP 8.2 Manchester conference, to highlight differences in positivist and interpretive research assumptions. While Orlikowski and Gash did not rule out quantitative approaches to studying technological frames, their intent was to advance process theories of IT in organizations, in which humans' interpretations of IT play an analytic and theoretic role. Quantitative data collection and analysis are typically used to measure constructs and test variance theories hypotheses. Use of these methods might make the technological frames concept more appealing to positivist researchers and promote its wider use, but the studies would be quite different from the interpretive studies that have thus far characterized TFR research. Whether quantitative TFR studies (positivist or interpretive) would be more informative, or even as informative, to practitioners as wellorganized qualitative feedback remains to be demonstrated. 


\subsection{Do We Really Understand Frame Incongruence?}

Identifying frame incongruence and its consequences was a major contribution Orlikowski and Gash posited from TFR analysis. Subsequent TFR studies have focused almost exclusively on these issues. While incongruence is important, merely noting that different groups think differently about information technologies, and that differences can cause problems, is not very satisfying in the long run. ${ }^{2}$ The TFR framework does not address frame structure or structural aspects of incongruence, and subsequent studies have skirted these questions. Moreover, the assumption that incongruence is necessarily detrimental has not been critically examined. Organizational social cognitive research provides some evidence that heterogeneity in frames may be inconsequential or even beneficial in some circumstances (Walsh et al. 1988).

How could the conceptual definition and implications of incongruence be refined in TFR research? Given the prevalence of problematic IS implementation projects, there should be no difficulty finding research sites where incongruence abounds. Cognitive mapping and analysis methods such as MDS or repertory grid techniques could be helpful to develop measures of and analyze incongruence. Longitudinal case studies would make it easier to monitor emerging incongruence, particularly if incongruence shifts over time, as Davidson (2002) suggests. However, longitudinal field research is a risky prospect, particularly since the phenomena of research interest may not develop in a particular case or during the timeframe of a field study. Short-term case studies reduce the time investment and allow some retrospective TFR analysis, but they are subject to the limitations we outlined earlier. This makes it difficult to assess frame change or change incongruence.

Perhaps more importantly, post hoc explanations of what went wrong are of limited value to practitioners dealing with the consequences of failed projects. One solution to this dilemma, which could help researchers assess how critical a role and what types of roles incongruence actually plays in organizational IS/IT activities, is action research. We will not attempt to review the benefits and limitations of action research here but merely point out that action research approaches are gaining legitimacy within IS academic circles and can enhance the practical relevance of IS research (Avison et al. 1999). In an action research project, TFR researchers would work with practitioners during IS/IT project activities to assess TFRs and to plan, monitor, and adjust interventions, such as tackling frame incongruence. By observing, taking action, and observing outcomes, researchers could elicit the phenomena they are interested in for research purposes and observe unfolding cause/effect processes. In these ways, they would be able to assess the effectiveness of TFR analysis for improving organizational outcomes. As Tan and Hunter (2002) suggested, practitioners who participate in these projects could benefit directly.

${ }^{2}$ Thanks to Sussan Gasson for this insight. 


\subsection{Is There More to Technological Frames than Inconguence?}

While much theoretical work remains to be done on the concept of incongruence, we suggest the importance of frame incongruence in organizational IS/IT activities has been established in the IS literature by Orlikowski and Gash (1994) and subsequent studies, and that it is time to move on to new topics of theoretical interest. Walsh (1995) commented that when socio-cognitive structures matter in use, it becomes increasingly important to understand how they develop and change at individual, group and organizational levels. SCOT theory similarly highlights the importance of frame formation and change, particularly stabilization and closure. The TFR framework outlined by Orlikowski and Gash (1994) addressed these questions at a high level, noting only that individuals' frames develop and change through experience, education, and sometimes through planned interventions. The small body of TFR research we reviewed provided some additional insights, for example, how individuals' frames arise from cultural assumptions (Barrett 1999), are communicated or diffused though stories and metaphors (Davidson 2002), and change through social translation (Lin and Cornford 2000) and political processes (McLoughlin et al. 2000).

Sociologists like Meyer and Rowan (1977) and DiMaggio and Powell (1983) have emphasized the influence of external belief structures and cultural frames on actors. Powell and DiMaggio (1991) defined an organizationalfield as "those organizations that, in the aggregate, constitute a recognized area of institutional life: key suppliers, resources and product consumers, regulatory agencies, and other organizations that produce similar services or products" (pp. 64-65). Within this institutional domain, organizations share common meaning systems and interact primarily with each other. Scott commented that studies at the organizational field level of analysis are critical to understanding institutional logics - those widely held beliefs and socio-cultural structures that inform practice.

Individuals do construct and continuously negotiate social reality in everyday life, but they do so within the context of wider, pre-existing cultural systems: symbolic frameworks, perceived to be both objective and external, that provide orientation and guidance (e.g., Goffman 1974) (Scott 2001, p. 41).

Technological frames of actors - individuals, groups, and organizations - within an organizational field are shaped by the field's institutional logics.

We suggest it could be interesting and valuable to examine frame development and change at the organizational field levels of analysis, as Barrett (1999) did with his study of the London insurance market. Information systems and technologies are increasingly utilized in interfirm relationships and transactions; individual and organizational sensemaking related to IT innovation happens not only within firm boundaries, but also among firms. At this level of TFR analysis, IT vendors, customers/user organizations, academics, consultants, and other stakeholder groups become relevant social groups, whose sensemaking, actions, and interactions shape technological artifacts (Bijker 
1995). These frames (with regard to specific technological innovations) constitute the external belief structures that influence actors' frames within organizations. Understanding how frames develop, diffuse, and change within organizational fields could inform our understanding of technology-related change within industrial sectors as well as within particular organizations. Swanson and Ramiller (1997) have called for research at this level of analysis, using the term organizing vision to describe socially constructed interpretations of new technologies, the rationale for IT adoption, and shared expectations for how a new IT innovation will affect practices. This type of broad study of technological frames would move away from social cognitive research in the direction of SCOT research, where socio-technical theories such as actor-network theory (Latour 1987) could provide insights on frame change processes.

\section{CONCLUDING THOUGHTS AND REFLECTIONS}

Technological frames of reference research represents the type of IS endeavor that the 1984 Manchester IFIP 8.2 conference advocated: socially informed, organizationally based, methodologically rich, and relevant to practice. Although we did not find a wealth of TFR publications stemming from Orlikowski and Gash's (1994) seminal paper, we did find widespread interest in the TFR concept and a handful of significant studies, published in respected IS journals and outlets, conducted by a variety of IS researchers, many with ties to IFIP Working Group 8.2.

Despite its intuitive appeal and potential explanatory power, we may never see the level of research activity centered on the technological frames of reference concept as we have, for example, around the technology acceptance model. TFR studies as a genre are based on interpretive assumptions, labor-intensive qualitative research methods, organizational field studies, and, ideally, longitudinal research designs. Furthermore, TFR research is ideographic, making it difficult to leverage the researcher's investment in one study across multiple future studies. Much IS research is conducted from a positivist perspective, using controlled, quantitative data collection methods (laboratory studies, surveys) and statistical analysis techniques. "Publish or perish" tenure pressures in academia tend to favor these research approaches and productivity measured in number of publications. Given these institutional realities, there may be a limited market for the TFR concept as a basis of IT research. Adoption of mixed qualitative/quantitative methods such as multidimensional scaling or repertory grid analysis may increase the appeal of TFR analysis somewhat, among the broad audience of IT researchers.

Without the disciplinary innovations inspired and carried out by the IFIP 8.2 community over 20 years, notably greater acceptance of qualitative methods and interpretive approaches (Walsham 1995), technological frame research may never have taken root at all. Like the larger body of research carried out by IFIP 8.2 researchers and kindred spirits, TFR research has established a beachhead, set up camp, and conducted successful forays into the territory of the dominant paradigm. Much theoretical work remains to be done. In our analysis and discussion, we highlighted areas where TFR concepts and methods require further development and suggested three areas that we find promising for future study. We are hopeful that a similar analysis in another decade will reveal that the TFR research has continued to grow and to thrive. 


\section{REFERENCES}

Avison, D.; Lau, F.; Myers, M.; and Nielsen, P. “Action Research,” Communications of the ACM (42:1), 1999, pp. 94-98.

Barrett, M. I. "Challenges of EDI Adoption for Electronic Trading in the London Insurance Market," European Journal of Information Systems (8:1), 1999, pp. 1-15.

Bartunek, J. "Changing Interpretive Schemes and Organizational Restructuring: The Example of a Religious Order," Administrative Science Quarterly (29), 1984, pp. 355-372.

Bartunek, J., and Moch, M. "First Order, Second Order, and Third Order Change and Organization Development Interventions: A Cognitive Approach," Journal of Applied Behavioral Science (23), 1987, pp. 483-500.

Berger, P. L., and Luckmann, T. The Social Construction of Reality, New York: Anchor, 1967.

Bijker, W. Of Bicycles, Bakelites, and Bulbs: Towards a Theory of Sociotechnical Change, Cambridge, MA: MIT Press, 1995.

Bijker, W.; Hughes, T.; and Pinch, T. The Social Construction of Technological Systems, Cambridge, MA: MIT Press, 1987.

Boland, Jr., R. "Control, Causality and Information Systems Requirements," Accounting, Organizations and Society (4:4), 1979, pp. 259-272.

Boland, Jr., R. "The Process and Product of Systems Design," Management Science (24), 1978, pp. 887-898.

Bostrom, R., and Heinen, J. "MIS Problems and Failures: A Socio-Technical Perspective, Part I-The Causes," MIS Quarterly (1:1), 1977, pp. 17-32.

Daft, R., and Weick, K. "Toward a Model of Organizations as Interpretative Systems." Academy of Management Review (9:2), 1984, pp. 284-295.

Dagwell, R., and Weber, R. "System Designers' User Models: A Comparative Study and Methodological Critique," Communications of the ACM (26:11), 1983, pp. 987-997.

Davidson, E. "Technology Frames and Framing: A Socio-Cognitive Investigation of Requirements Determination" MIS Quarterly (26:4), 2002, pp. 329-358.

Davis, F. "Perceived Usefulness, Perceived Ease of Use, and User Acceptance of Information Technology," MIS Quarterly (13:3), 1989, pp. 318-340.

DiMaggio, P., and Powell, W. "The Iron Cage Revisited: Institutional Isomorphism and Collective Rationality in Organizational Fields," American Sociological Review (48), 1993, pp. 147-160.

Gallivan, M. "Meaning to Change: How Diverse Stakeholders Interpret Organizational Communication About Change Initiatives," IEEE Transactions on Professional Communication (44:4), 2001, pp. 243-266.

Ginzberg, M. "Early Diagnosis of MIS Implementation Failure: Promising Results and Unanswered Questions," Management Science (27:4), 1981, pp. 459-478.

Gioia, D. "Symbols, Scripts, and Sensemaking: Creating Meaning in the Organizational Experience," in H. Sims Jr., D. Gioia, and Associates (Eds.), The Thinking Organization, San Francisco: Jossey-Bass, 1986, pp. 49-74.

Goffman, I. Frame Analysis, New York: Harper, 1974.

Isabella, L. "Evolving Interpretations as a Change Unfolds: How Managers Construe Key Organizational Events," Academy of Management Journal (33:1), 1990, pp. 7-41.

Keil, M., and Robey, D. "Turning Around Troubled Software Projects: An Exploratory Study of the De-escalation of Commitment to Failing Courses of Action," Journal of Management Information Systems (15:4), 1999, pp. 63-88.

Khoo, M. "Community Design ofDLESE's Collections Review Policy: A Technological Frames Analysis," in Proceedings of the first ACM/IEEE-CS Joint Conference on Digital Libraries, Roanoke, VI, June 24-28, 2001. 
Krackhardt, D. “Cognitive Social Structures,” Social Networks (9), 1987, pp. 109-134.

Latour, B. Science in Action, Boston: Harvard University Press, 1987.

Lin, A., and Cornford, T. "Framing Implementation Management," in W. J. Orlikowski, S. Ang, P. Weill, H. C. Krcmar, and J. I. DeGross (Eds.), Proceedings of the $21^{\text {st }}$ International Conference on Information Systems, Brisbane, Australia, 2001, pp. 197-205.

Markus, M. L., and Bjørn-Andersen, N. "Power Over Users: Its Exercise by System Professionals," Communications of the ACM (30:6), 1987, pp. 498-504.

McLoughlin, I.; Badham, R.; and Couchman, P. "Rethinking A-Political Process in Technological Change: Socio-Technical Configurations and Frames," Technology Analysis \& Strategic Management (12:1), 2000, pp., 17-37.

Meyer, J., and Rowan B. "Institutional Organizations: Formal Structure as Myth and Ceremony," The American Journal of Sociology (83), 1977, pp. 340-363.

Orlikowski, W. "The Duality of Technology: Rethinking the Concept of Technology in Organizations," Organization Science (3:2), 1992, pp. 398-427.

Orlikowski, W., and Gash, D. "Technology Frames: Making Sense of Information Technology in Organizations," ACM Transactions on Information Systems (12:2), 1994, pp. 174-207.

Porac, J.; Thomas, H.; and Baden-Fuller, C. "Competitive Groups as Cognitive Communities: The Case of Scottish Knitwear Manufacturers," Journal of Management Studies (26:4), 1989, pp. 397-416.

Powell, W., and Dimaggio, P. J. The New Institutionalism in OrganizationalAnalysis, Chicago: University of Chicago Press, 1991.

Sahay, S.; Palit, M.; and Robey, D. "A Relativist Approach to Studying the Social Construction ofInformation Technology," European Journal ofInformation Systems (3:4), 1994, pp. 248258.

Scott, W. Institutions and Organizations ( $2^{\text {nd }}$ ed.), Thousands Oaks, CA: Sage Publications, 2001.

Shaw, N.; Lee-Partridge, J.; and Ang, J. S. K. "Understanding End-User Computing through Technological Frames," in K. Kumar and J. I. DeGross (Eds.), Proceedings of the $\mathbf{1}^{\text {th }}$ International Conference on Information Systems, Atlanta, GA, 1997, pp. 453-459.

Swanson, E., and Ramiller, N. "The Organizing Vision in Information Systems Innovation," Organization Science (8:5), 1997, pp. 458-474.

Tan, F. and Hunter, M. "The Repertory Grid Technique: A Method for the Study of Cognition in Information Systems," MIS Quarterly (26:1), 2002, pp. 39-57.

Walsh, J. "Managerial and Organizational Cognition: Notes from a Trip Down Memory Lane," Organization Science (6:3), 1995, pp. 280-321.

Walsh, J., and Farley, L. "The Role of Negotiated Belief Structures in Strategy Making," Journal of Management (31), 1986, pp. 873-896.

Walsh, J.; Henderson, C.; and Deighton, J. "Negotiated Belief Structures and Decision Performance: An Empirical Investigation," Organizational Behavior and Human Decision Processes (42), 1988, pp. 194-216.

Walsham, G. "The Emergence of Interpretivism in IS Research," Information Systems Research (6), 1995, pp. 376-394.

Weick, K. The Social Psychology of Organizing, Reading, MA: Addison-Wesley, 1979.

Weick, K., and Bougon, M. "Organizations as Cognitive Maps: Charting Ways to Success and Failure," in H. Sims Jr., D. Gioia, and Associates (Eds.), The Thinking Organization, San Francisco: Jossey-Bass, 1986, pp. 102-135. 


\begin{abstract}
ABOUT THE AUTHORS
Elizabeth J. Davidson is an associate professor in the Department of Information Technology Management at the University of Hawaii. In her research, she has examined how organization members conceptualize opportunities for using information technology and negotiate IT development initiatives. She is currently studying teamwork in global IT support and the use of information technologies in scientific research. Elizabeth has extensive experience as a project manager and business analyst in the information technology industry in the United States. She can be reached at davidson@cba.hawaii.edu.

David Pai is a doctoral candidate in the Communications and Information Sciences program at the University of Hawaii. His research interests include adoption, implementation and use of information technologies, cognitive aspects of human-computer interaction, and symbiotic nature of IS research paradigms. David has a Master's degree in MIS, and prior to entering academia, he worked as lead engineer developing rocket engine systems.
\end{abstract}

